\title{
Minimal Invasive Management of Gallbladder Perforation
}

\author{
Jalbaji P More ${ }^{1}$, Shirish R Bhagvat ${ }^{2}$, Prachiti Gokhe ${ }^{3}$, Amol Wagh $^{4}$, Ajay H Bhandarwar ${ }^{5}$
}

\begin{abstract}
Background: Gallbladder perforation (GBP) is a rare clinical entity but life-threatening complication of cholecystitis with or without stones and associated with increased rate of mortality and morbidity due to late diagnosis.

Case description: We describe the case of a 51-year-old male patient who presented with abdominal pain and a Niemeier type II GBP. CT scan revealed a GBP with subhepatic collection and surrounding inflammatory changes. It was communicating through a thin hypodense band with the cystic duct, distal to an impacted stone. Through laparoscopy, the collection was confirmed to be a subhepatic secondary to GBP. The cholecystectomy and the abscess cavity treatment were completely handled via laparoscopic approach.

Discussion and conclusion: The case report demonstrates that laparoscopic approach can be a safe and feasible method in order to treat both the cause and the complication in this situation. Early diagnosis and appropriate minimally invasive approach are the key to manage this condition. Keywords: Gallbladder perforation, Laparoscopic cholecystectomy, Niemeier classification.

World Journal of Laparoscopic Surgery (2019): 10.5005/jp-journals-10033-1364
\end{abstract}

\section{INTRODUCTION}

In retrospective studies, acute cholecystitis may result in 2-12\% of gallbladder perforation (GBP). The most important risk factor is gallbladder stones. ${ }^{1}$

According to the inflammation progress and type of perforation, Niemeier is subdivided GBP into three types. ${ }^{1,5-7}$ Type I (acute) is associated with free perforation into the peritoneal cavity. Type II (subacute) perforation consists in the localization of the fluid at the perforation site, pericholecystic abscess, and localized peritonitis. If the perforation site is covered by the omentum, the intestines, or the visceral surface of the liver, the infection remains limited in the supra mesocolic space with formation of a plastron, pericholecystic fluid, or an intrahepatic abscess. ${ }^{1-3}$ Therefore, the GBP can cause a cholecystohepatic communication with consequent spreading of the infection into the liver. The type III (chronic) perforation consists of internal or external fistula formation. ${ }^{1,3,5}$

\section{Case Description}

A 51-year-old male presented to us with complaints of low-grade fever, pain in right hypochondrium since14 days and h/o weight loss. On physical examination, the patient was icteric and Murphy's sign was positive. His white blood cell count was $15,400 / \mu \mathrm{L}$ and total bilirubin was $5.1 \mathrm{mg} \%$ with the direct component being $3.4 \mathrm{mg} \%$. Alkaline phosphatase level was $812 \mathrm{lU} / \mathrm{L}$. Ultrasound is ultrasonography report of abdomen which was suggestive of thickened GB wall with pericholecystic collection gallbladder perforation (GBP). This was further investigated with a triphasic CT scan which showed GBP over posterior wall with subhepatic collection. Patient was prepared for early elective laparoscopic cholecystectomy the following day.

The umbilical port was inserted by Hasson's method. The intraoperative findings revealed liver adhesions between inferior edge of right lobe of liver and omentum. There were omental adhesions to gallbladder with increased vascularity. Around $50 \mathrm{cc}$ pus mixed with bile was there, aspirated, and sent for culture. After initial adhesiolysis, calots was found to be frozen. Significant inflammation was encountered in Calot's triangle with a short and wide cystic duct. So antegrade dissection of gallbladder

\begin{abstract}
${ }^{1-4}$ Department of General Surgery, Grant Government Medical College and Sir JJ Group of Hospitals, Mumbai, Maharashtra, India

${ }^{5}$ Department of General, Bariatric, GI, HPB, Endocrine MIS, Grant Government Medical College and Sir JJ Group of Hospitals, Mumbai, Maharashtra, India
\end{abstract}

Corresponding Author: Jalbaji P More, Department of General Surgery, Grant Government Medical College and Sir JJ Group of Hospitals, Mumbai, Maharashtra, India, Phone: +91 9960672080 , e-mail: morejalbaji97@gmail.com

How to cite this article: More JP, Bhagvat SR, Gokhe P, et al. Minimal Invasive Management of Gallbladder Perforation. World J Lap Surg 2019;12(1):45-47.

Source of support: Nil

Conflict of interest: None

approach is preferred, and while separating the gallbladder off the gallbladder fossa, the posterior (hepatic) surface of gallbladder at fundus found to be ruptured. The gallbladder fossa was irrigated with saline and mopped using a gauze piece. The frozen calots was meticulously dissected using standard laparoscopic instruments (suction cannula) and electrocautery. The critical view of safety was achieved. Cystic artery and cystic duct were clipped and divided, and total cholecystectomy was performed. Hemostasis was achieved and tube drain was placed in Morrison's pouch.

The postoperative course was uneventful, the drain was removed on day 2 , and patient discharged on day 4 . The histopathology report was chronic eosinophilic cholecystitis with GBP.

\section{Discussion}

GBP is a rare complication of acute cholecystitis and cholelithiasis and still remains a diagnostic challenge to surgeons. Of all the patients with cholelithiasis, approximately $10 \%$ have asymptomatic cholelithiasis of which $2 \%$ may present with a GBP, and mortality in patients with a perforation is $12-16 \% .{ }^{4}$ GBP was classified and described by Neimeier in three types (Table 1). ${ }^{5}$ 
There are several mechanisms behind GBP. The most common is cystic duct obstruction, gallbladder distension, altered vascularization, ischemia, and necrosis followed by perforation.

Fundus of the gallbladder is the most common site of perforation secondary to its poor blood supply. GBP can represent

Table 1: Neimeier classification of gallbladder perforation

\begin{tabular}{lll}
\hline Type & State & Description \\
\hline Type I & Acute & $\begin{array}{l}\text { Is associated with generalized biliary } \\
\text { peritonitis }\end{array}$ \\
Type II $\quad$ Subacute & $\begin{array}{l}\text { Consists of fluid localization at perforation } \\
\text { site, pericholecystic abscess } \\
\text { Includes the formation of internal or external } \\
\text { Type III } \quad \text { Chronic }\end{array}$ \\
\hline
\end{tabular}

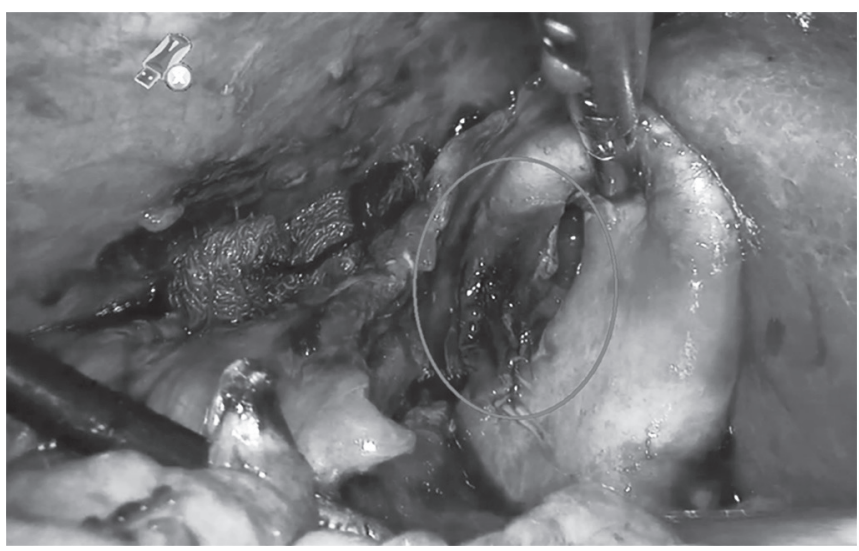

Fig. 1: Perforation in gallbladder at fundus
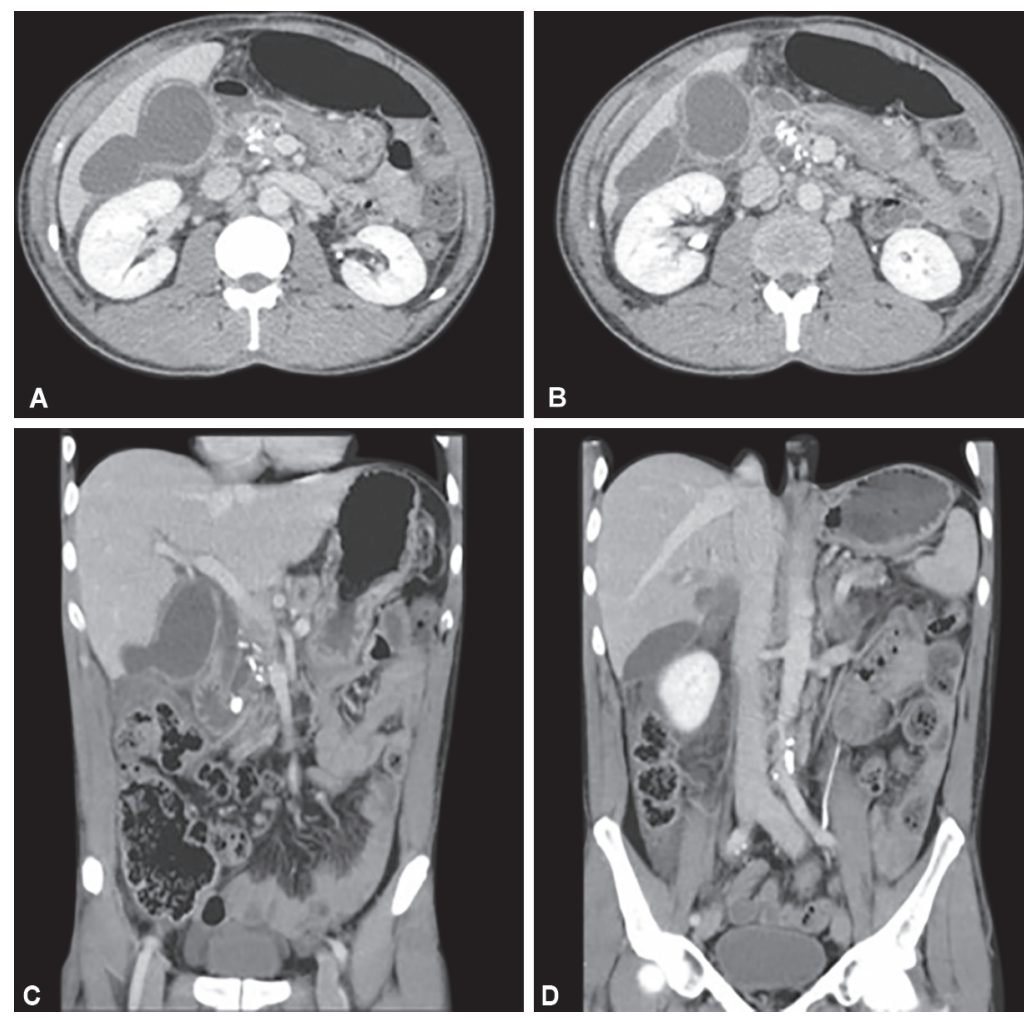

in a number of sign and symptoms including generalized or right upper quadrant pain, fever, and jaundice.

Patients can also present with generalized peritonitis and septic shock.

Gore et al. suggested that GBP should be suspected in patients of acute cholecystitis who suddenly deteriorated and become toxic. $^{8}$

Ultrasonography is the initial radiological investigation done in most of the cases, but it has its own limitations in suspected cases of GBP due to gaseous distension of bowel and pain; sonography is compromised and unable to locate the perforation. CT scan is considered the gold standard for the diagnosis of complicated biliary pathology. ${ }^{10}$ Signs of GBP on CT scan include a defect, thickening, and enhancement in gallbladder wall and gall stones in common bile duct and cystic duct. Pericholecystic changes include fat stranding, fluid collection, abscess, or bilioma formation (Figs 1 and 2).

Kim et al. in their study compared sensitivity of CT and ultrasound in detecting the perforation found that in $50 \%$ of patients, and site of perforation was seen on CT but not a single perforation was identified on sonography. ${ }^{9}$

MRI examination, by its superior soft tissue resolution and multiplanar capability, can be a possible diagnostic option in order to demonstrate the defects of the gallbladder wall; however, cost is the limiting factor.

In our case, we did a thorough routine and radiological workup to establish a definite diagnosis. Considering the safety and feasibility of laparoscopic cholecystectomy, it was preferred. Early laparoscopic cholecystectomy is a safe option in acute cholecystitis patient. Hussain et al. in their study of GBP have concluded that initial management can be conservative followed by interval cholecystectomy. ${ }^{11}$ Donati et al. in a case report of GBP suggest that early intervention or open cholecystectomy should be performed. ${ }^{12}$

Fig. 2: CT scan images; coronal view showing gallbladder perforation 


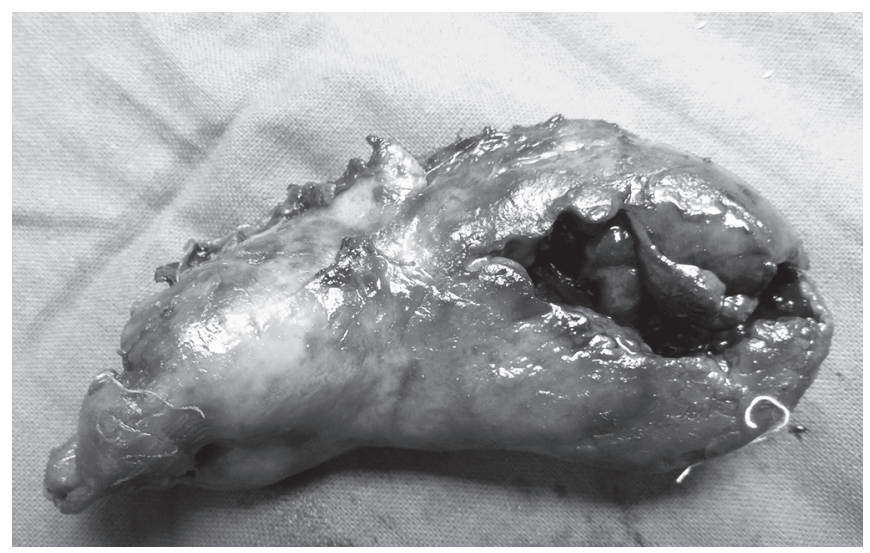

Fig. 3: Perforated gallbladder specimen

Our case report successfully demonstrates the utility of laparoscopy in GBP and its ability to treat the disease as well as complication in the same setting.

Considering the technically demanding nature of laparoscopic surgery in such situations, it is advisable that it should be performed by an experienced laparoscopic surgeon. After cholecystectomy, gallbladder fossa is irrigated with normal saline and an abdominal drain tube is placed under laparoscopic guidance. The postoperative hospital stay in our case was only 4 days (Fig. 3).

\section{CONCLUSION}

A rapid, multimodal diagnostic workup and accurate identification of the type of GBP will help clinicians in identifying the best effective means of managing patients with such pathology. An appropriate minimally invasive approach is the key to manage this rare complication. Early laparoscopic cholecystectomy can be a definitive management option in GBP patient.

\section{References}

1. Masood MR, Ali M, Burgaul R, et al. Hepatic abscess secondary to gallbladder perforation: case report and literature review. Scott Med J 2008;53(1):60. DOI: 10.1258/RSMSMJ.53.1.60H.

2. Derici $H$, Kara C, Bozdag AD, et al. Diagnosis and treatment of gallbladder perforation. World J Gastroenterol 2006;12(48): 7832-7836. DOI: 10.3748/wjg.v12.i48.7832.

3. Grigoroiu M, lonescu M, Braæoveanu V, et al. Pyogenic liver abscess. Evaluation of the changes in etiology, diagnosis, treatment and evolution. Chirurgia (Bucur) 2000;95(6):511-521. Romanian.

4. Date RS, Thrumurthy SG, Whiteside S, et al. Gallbladder perforation: case series and systematic review. Int J Surg 2012;10(2):63-68. DOI: 10.1016/j.ijsu.2011.12.004.

5. Niemeier OW. Acute free perforation of the gallbladder. Ann Surg 1934;99(6):922-924. DOI: 10.1097/00000658-193499060-00005.

6. Göbel T, Kubitz R, Blondin D, et al. Intrahepatic type II gall bladder perforation by a gall stone in a CAPD patient. Eur J Med Res 2011;16(5):213-216. DOI: 10.1186/2047-783X-16-5-213.

7. Kochar K, Vallance K, Mathew G, et al. Intrahepatic perforation of the gall bladder presenting as liver abscess: case report, review of literature and Niemeier's classification. Eur J Gastroenterol Hepatol 2008;20(3):240-244. DOI: 10.1097/MEG.0b013e3282eeb520.

8. Gore RM, Ghahremani GG, Joseph AE, et al. Acquired malposition of the colon and gall bladder in patients with cirrhosis: CT findings and clinical implications. Radiology 1989;171(3):739-742. DOI: 10.1148/ radiology.171.3.2717745.

9. Kim PN, Lee KS, Kim IY, et al. Gall bladder perforation:comparison of US findings with CT. Abdomen Imaging 1994;19:239-242.

10. Sood BP, Kalra N, Gupta S, et al. Role of sonography in the diagnosis of gall bladder perforation. J Clin Ultrasound 2002;30(5):270-274. DOI: $10.1002 /$ jcu.10071.

11. Hussain T, Adams M, Ahmed M, et al. Intrahepatic perforation of the gallbladder causing liver abscesses: case studies and literature review of a rare complication. Ann R Coll Surg Engl 2016;98(6):e88-e91. DOI: 10.1308/rcsann.2016.0115.

12. Donati $M$, Biondi $A$, Basile $F$, et al. An atypical presentation of intrahepatic perforated cholecystitis: a modern indication to open cholecystectomy. Report of a case. BMC Surgery 2014;14:6. DOI: 10.1186/1471-2482-14-6. 